\title{
Research Paper \\ Exploring the Viewpoint and Experience of College Students About Living With Grandparents
}

\author{
Maryam Chehrehgosha ${ }^{1}$, Leyla Jouybari ${ }^{2}$, Fariba Enayat ${ }^{3}$, ${ }^{*}$ Akram Sanagoo ${ }^{4}$, Behzad Taghvakish $^{1}$, Manouchehr Ardjomand Hessabi ${ }^{5}$
}

1. Department of Nursing, School of Nursing \& Midwifery, Golestan University of Medical Sciences, Gorgan, Iran

2. Department of Nursing, Education Development Center, School of Nursing \& Midwifery, Golestan University of Medical Sciences, Gorgan, Iran.

3. Department of Nursing, Student Research Committee, School of Nursing \& Midwifery, Golestan University of Medical Sciences, Gorgan, Iran.

4. Department of Nursing, Nursing Research Center, School of Nursing \& Midwifery, Golestan University of Medical Sciences, Gorgan, Iran.

5. Center for Clinical and Translational Sciences, University of Texas, Texas, USA.

Crtation: Chehrehgosha M, Jouybari L, Enayat F, Sanagoo A, Taghvakish B, Ardjomand Hessabi M. [Exploring the Viewpoint and Experience of College Students About Living With Grandparents (Persian)]. Iranian Journal of Ageing. 2016; 11(3):416-423. http://dx.doi.org/10.21859/sija-1103416

doi: : http://dx.doi.org/10.21859/sija-1103416

Received: 24 Mar. 2016

Accepted: 14 Jul. 2016

Key words:

Grandparents,

Older people, Stu-

dents, Experience,

Attitude

\section{A B STRACT}

Objectives The relationship between grandparents and grandchildren is an important and sensitive issue. Exploring grandchild's experiences can demonstrate and throw light on the relationship of two generations and form the basis of familial interactions. Therefore, this study aimed to explore the viewpoint and experience of college students about living with their grandfathers and grandmothers.

Methods \& Materials In this qualitative study, 50 college students were selected via purposeful sampling method. The students were interviewed to find answers about their viewpoint and experience of living with grandparents. All the interviews were conducted in scripted form; Then the data were coded and analyzed with content analysis method.

Results Content analysis showed dichotomy in sense of students about grandfathers and grandmothers. Two main themes were obtained "kindness and compassion" and "annoyance and offense". Subthemes of "kindness and compassion" were "spiritualty", "patient," and "unsparing love". Subthemes of "annoyance and offense "were "familial prejudice," "interfere in works," and "gripe."

Conclusion This experience was instructive for students. It was important that parents behave as the connecting path for this two generation and shape personality of this generation. 


\title{
بررسى ديدَّاه و تجربيات دانشجويان از زندگى با يدربزر تى و مادربزرَى سالمند
}

مريم جهرهكثا'، ليلا جويبارى '، فريبا عنايت"، "اكرم ثناكو"، بهزاد تقواكيش'، منوجهر ارجمند حسابىه

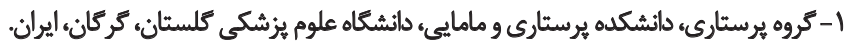

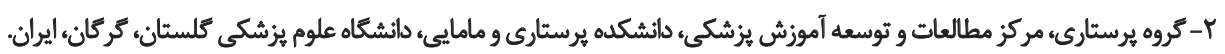

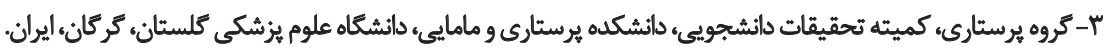

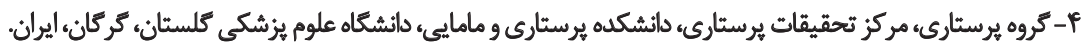

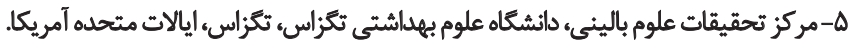

\begin{abstract}
حكبد

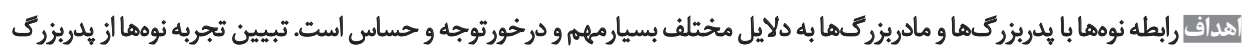

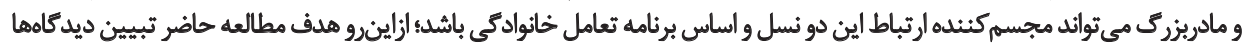

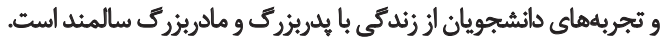

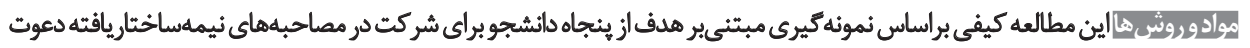

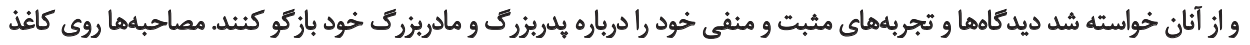

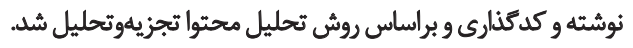

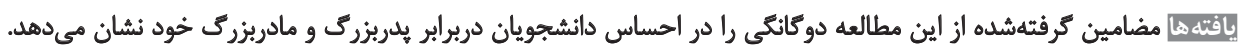

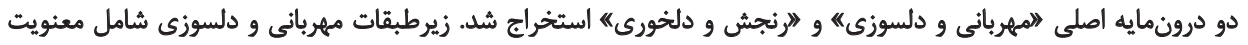

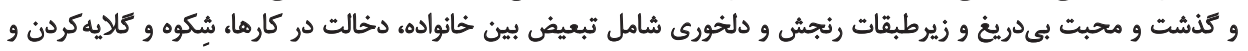
ركتويع بوده است.

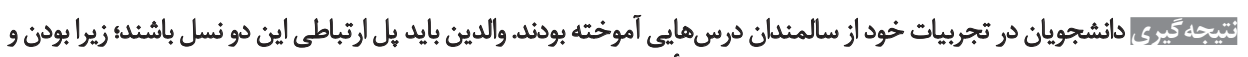

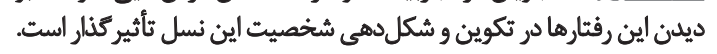

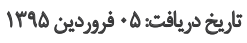

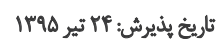

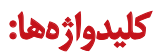

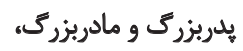

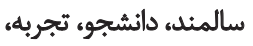
نكارش

كاهش يافته است. اين تغييرات شامل هستهاىشدن خانوادوادها،

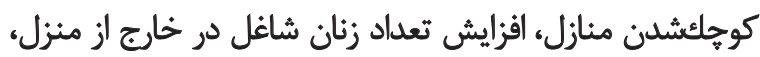

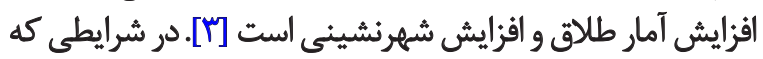

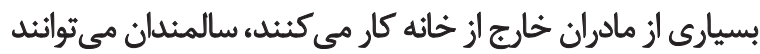

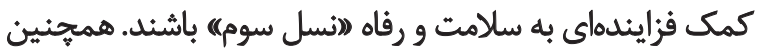

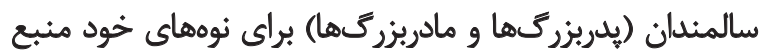

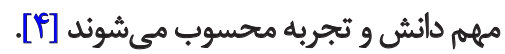

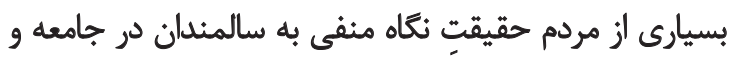

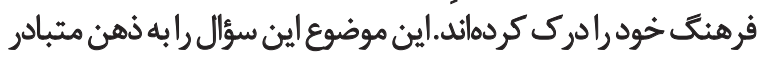

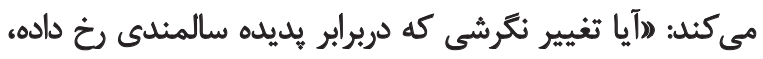

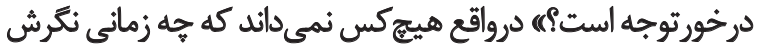

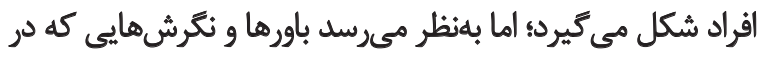

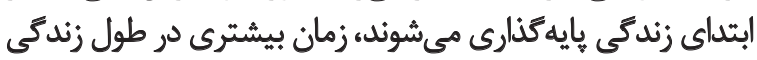

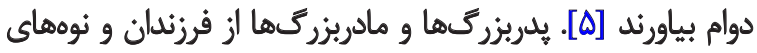

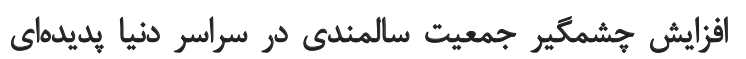

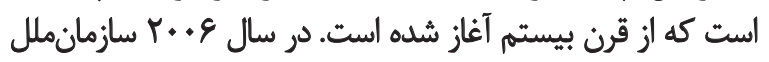

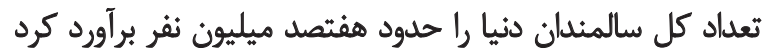

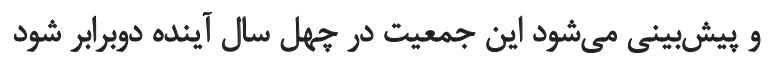

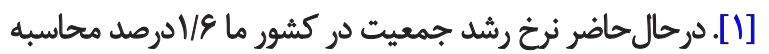

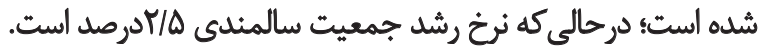

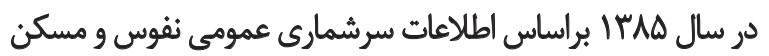

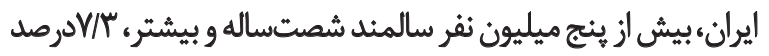

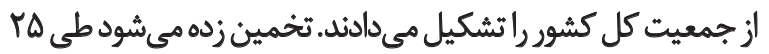

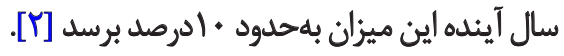

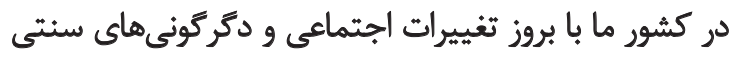
مشكلات سالمندان افزايش و درمقابل مراقبت خانواده از آنان 
مطالعه تجربه حضور در كنار يدربزرى و مادربزر مَ خود راداشتند.

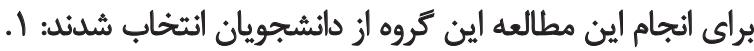

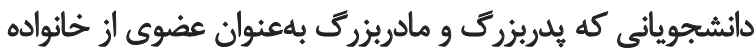

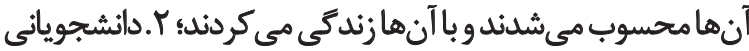

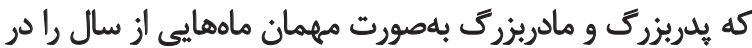

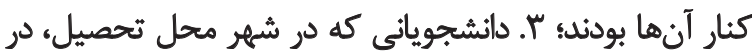
منزل بدربزرى و مادربزرى خود ساكن بودند.

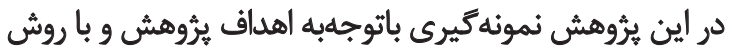

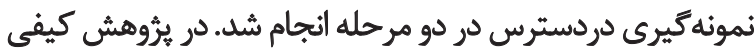

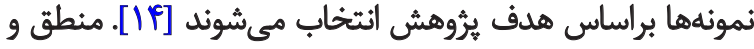

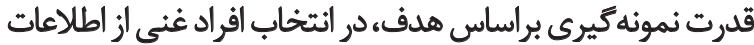

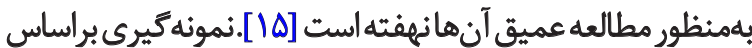

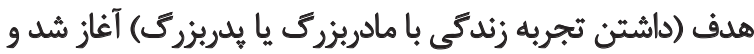

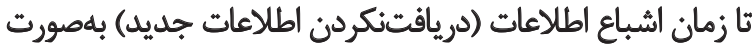
نمونه كيرى نظرى ادامه يافت. درمجموع شمار شركت كنثند إنان در

$$
\text { يُروهش به ينجاه نفر رسيد. }
$$

مدت مصاحبهها سى تا بنجاه دقيقه بود. مصاحبهها ضبط و و

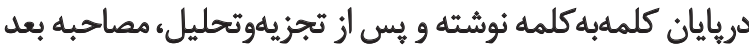

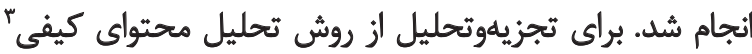

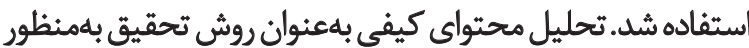

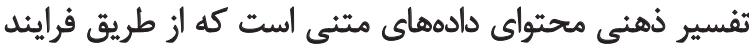

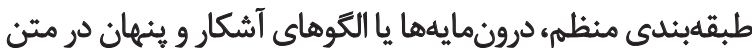

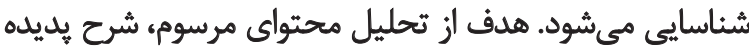

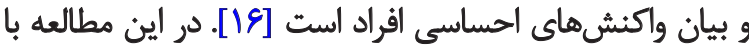

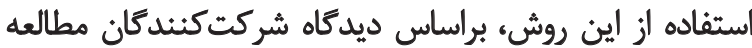

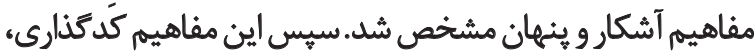

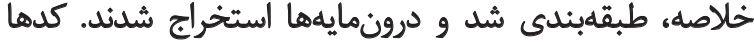

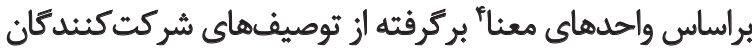

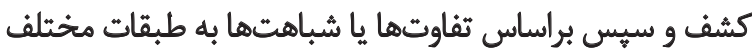

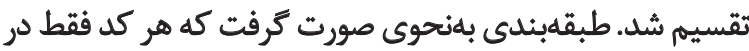

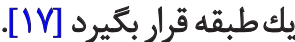

براى جمع آورى دادهها از مصاحبه نيمهساختاريافته استفاده شد.

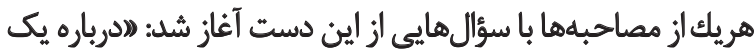

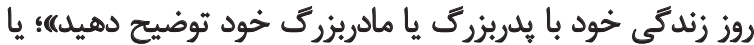

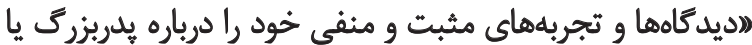

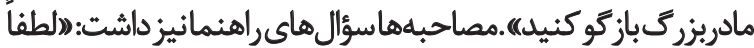

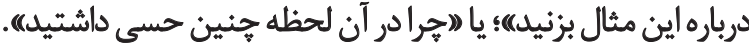

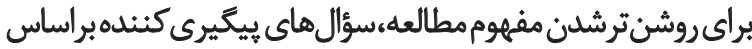

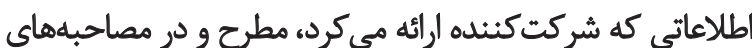

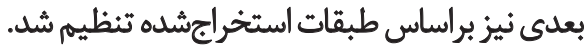

3. Qualitative content analysis
خود حمايتهاى مالي و عاطفى و مشاورهاي مى كنيند؛ بهعبارت تديكر

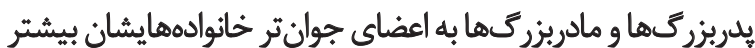

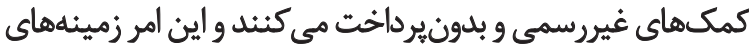
تماس بين اعضاى خانواده را فراهم مي آورد [F] امروزه در كذار از جامعه سنتى به بيشرفته، سالمندى نه به باله

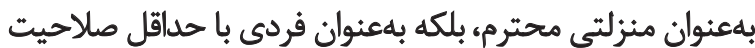

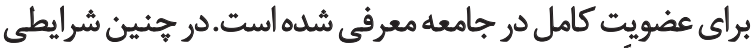

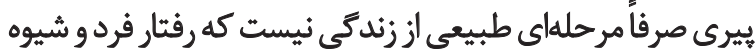

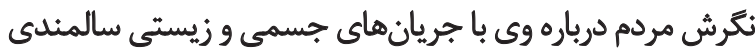

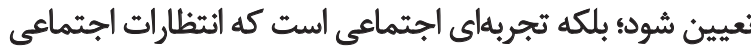
آن راتعيين مى كند [9].

مطالعات بسيارى به سالمندو سالمندي درحيطهنكرش اجتماعي

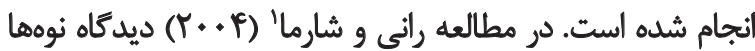

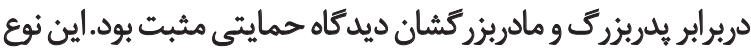

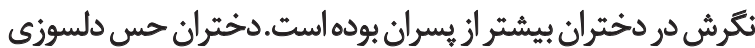

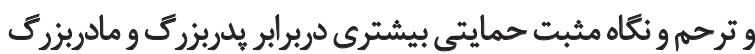

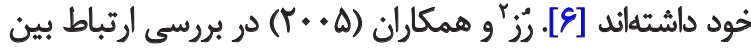

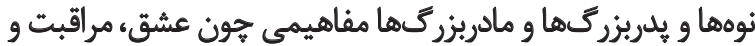

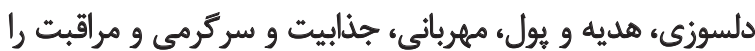

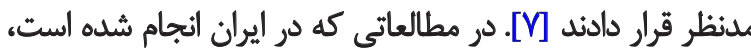

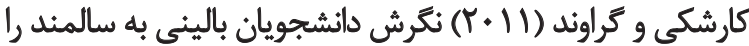

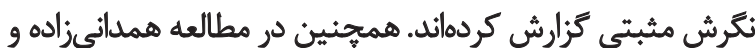

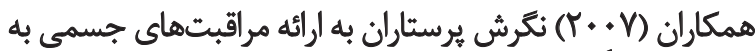

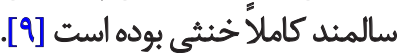
به دلايلى نظير ازبينرفتن خانواده كسترده، تحول نقش وطرئ فر فكر

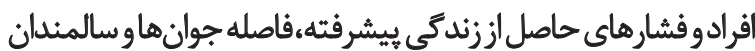

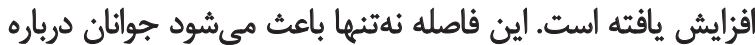

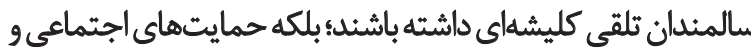

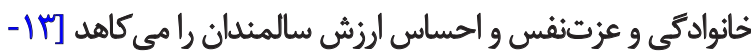

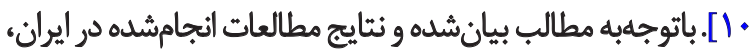

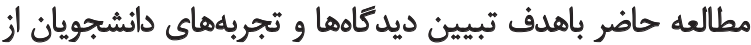

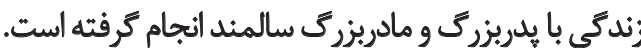

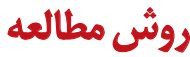

اين مطالعه با استفاده از مصاحبه عميق مفهوم يدربزرى

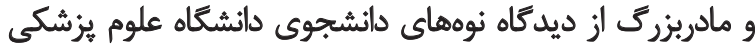

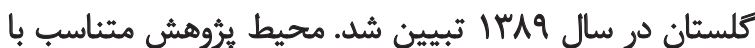

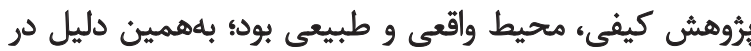

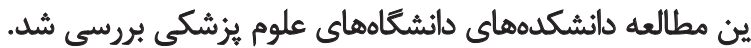

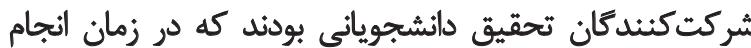

1. Rani and Sharma

2. Ross 


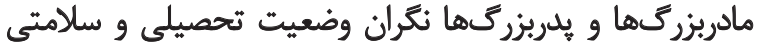

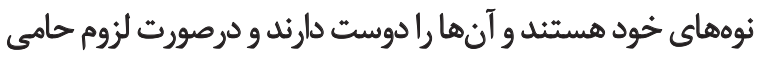

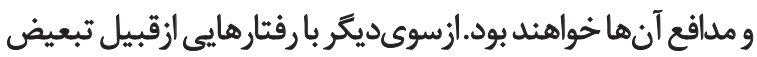

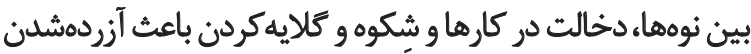

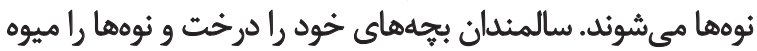

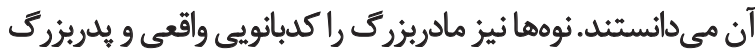

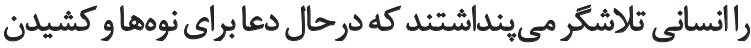

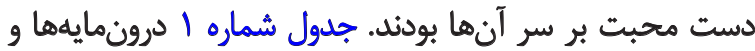
زيرطبقات اصلى اين مطالعه رانشان مى بـهد.

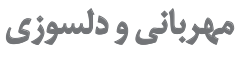

در ميان دوكانكى احساس ذكرشده، شركتكنيدكان در

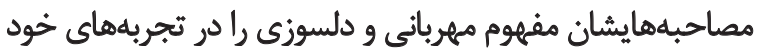

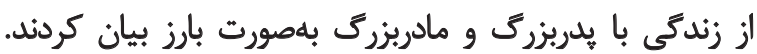

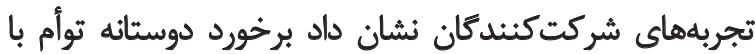

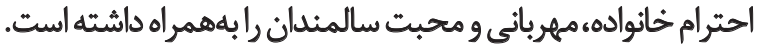

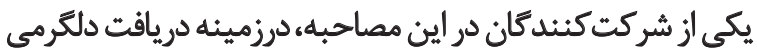

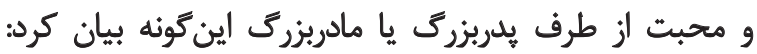

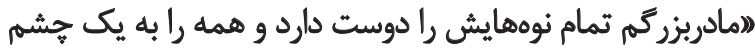

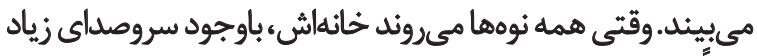

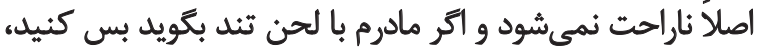

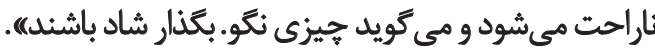

معنويث

بيشتر شركت كنندكان اين يُروهش تأكيد كردند كه اعتقاد

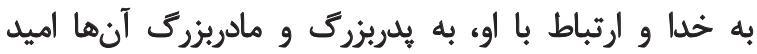

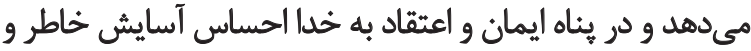

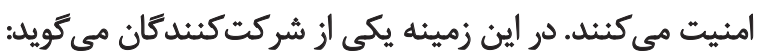

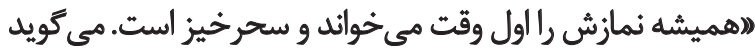

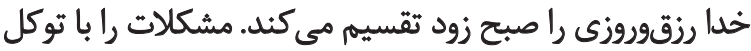

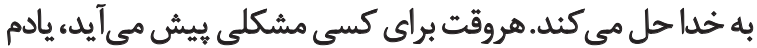

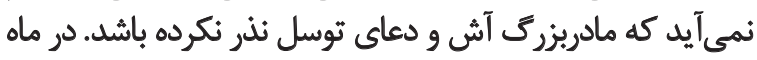

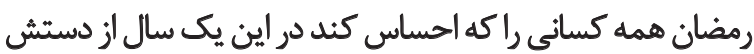

درابتدا هدف تحقيق و روش مصاحبه و حق افراد دربرابر

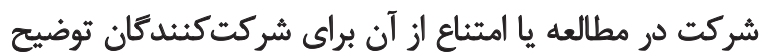

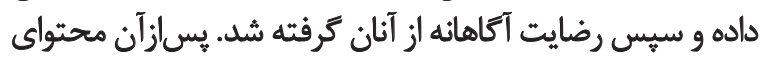

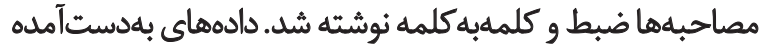

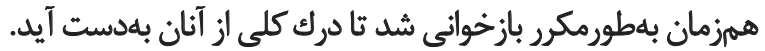

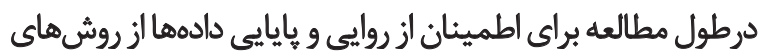

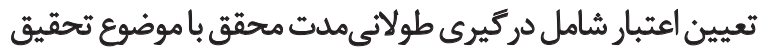

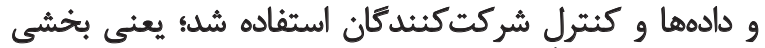

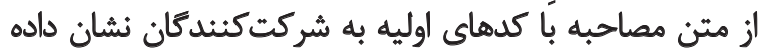

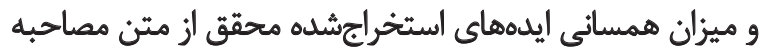

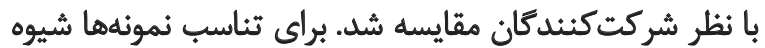

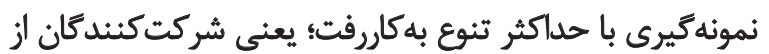
نظر سن، جنس، تحصيلات و رشته تحصيلى انتخاب شدندا ئند

ناظران خارجى آشنا به تحقيق كيفى، ثأييديذيرى يافتهها

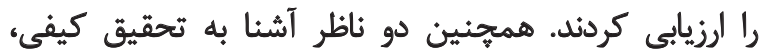

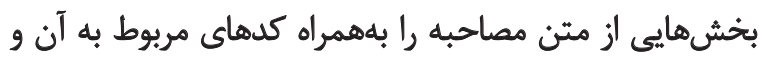

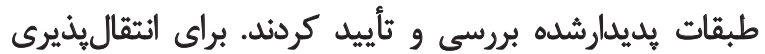

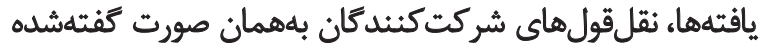

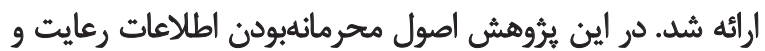

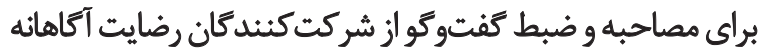

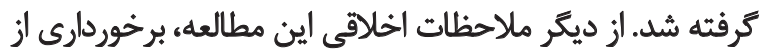

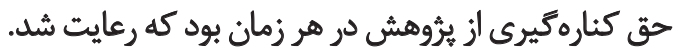

يافتهها

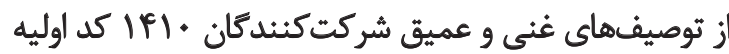

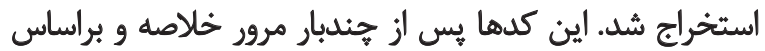

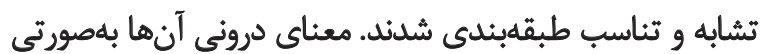

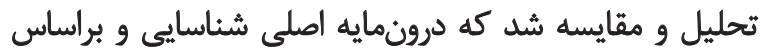
ماهيت بلصورت مفهوميى وانتزاعى نام كذاري شد.مضامين برك درفئه

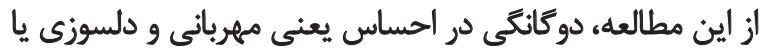

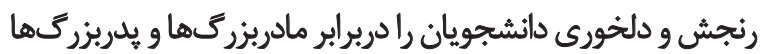

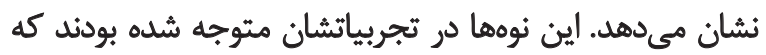

جدول ا. مضامين اصلى و فرعى مطالعه.

\begin{tabular}{|c|c|c|}
\hline زيرطبقات & طبقات اصلى & \\
\hline معنويت & \multirow{3}{*}{ مهربائى و دلسوزى } & \\
\hline كذشت و صبورى & & \\
\hline محبت بىدريغ & & \\
\hline تبعالت برين خارهاده & \multirow[b]{2}{*}{ رنجش و دلخورى } & $\underline{c}$ \\
\hline ركت شكوهوه و ولايهكردن & & $\underline{c}$ \\
\hline
\end{tabular}

L 
هيجوقت نشده كه به خانهاش برويمو وا اخم كند يا بهكونهاى رفتار كند

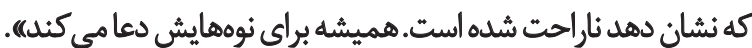

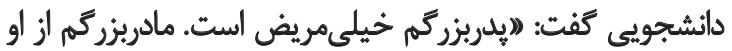

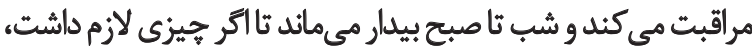

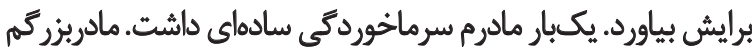

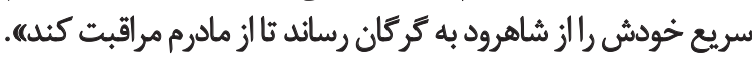

$$
\text { رنجش و دلخورى }
$$

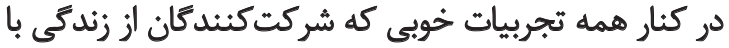

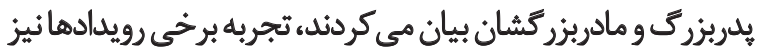

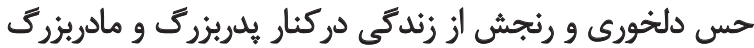

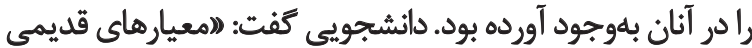

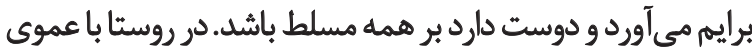

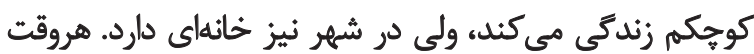

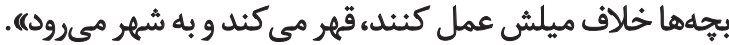
دراينباره يكى از شركت كنئدكان اينكونه بيان كرد: "ايكبار

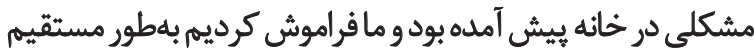

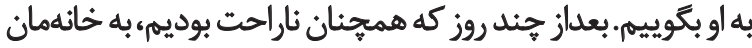

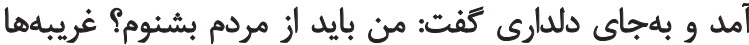
نزديكترند. خودش بهل زخم ما نمك مي مياجيدها. شركت كننده ديكرى جنين مي گفتت: لاوقتى تصميم به كارى

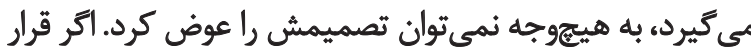

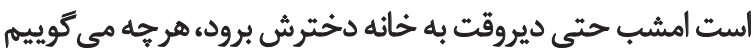
بمان، او جواب منفى مي دهد و مي كويد بائ بايد برومج). تبعيض بين خانواده رفتتار متفاوت يدربزرى و مادربزرى با نوهها و اعضاى خانواده و

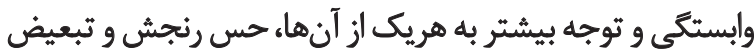

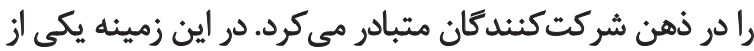

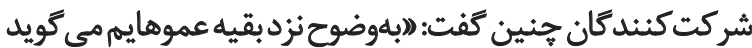

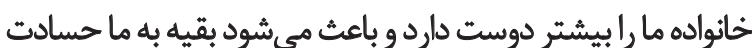

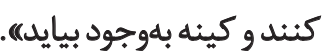
شركت كننده ديكرى نيز تجربه خود رالين كونه بيان كرد: (امن

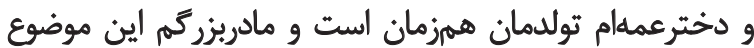

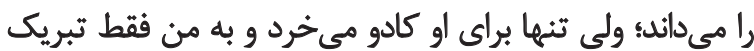

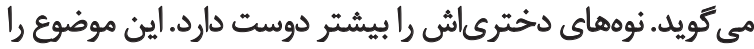

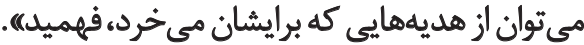

اعمال انظر در كارها سالمندان باتوجهبه كذّر سن و تجربه بيشترى كه در امور دارند،

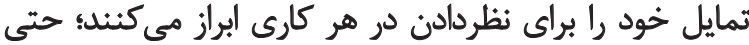

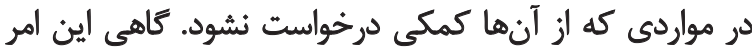

$$
\text { ناراحت شداند، به افطار دعوت مى كنده). }
$$

شركت كنتده ديكرى مي كفت: (اوقتى عمويم تصادف كرده بوده،

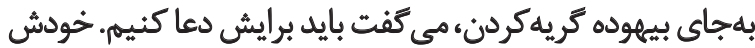

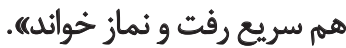

كَذشت و مبورى

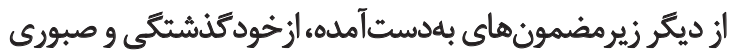

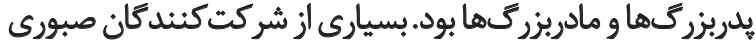

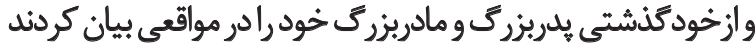

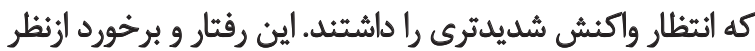

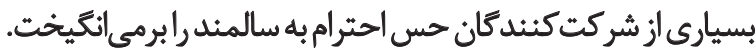

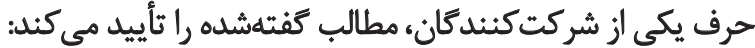

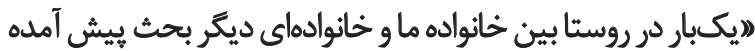

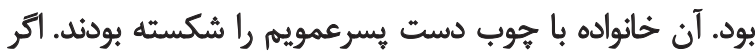

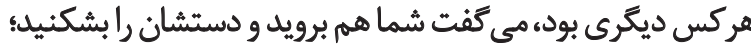

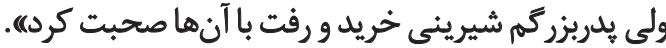
دانشجويي ديكر اين كونه بيان كرد: (اكر بين زن بعموهايم بحث

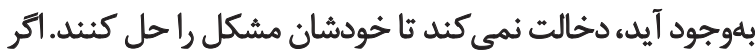

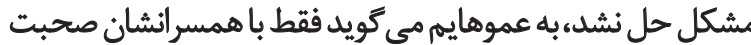

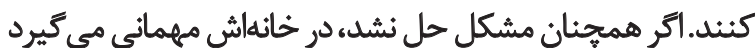
و با وساطت، مشكل راحل مئ كنده).

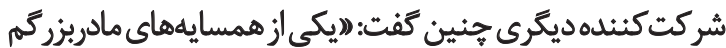

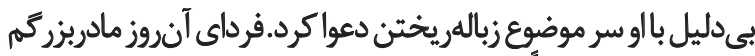

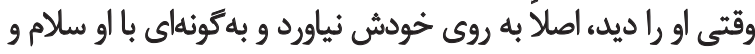
حواليرسى كرد كه همه همسايهها تعجب كرديندها.

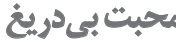

باتوجهبه ساختار فرهنكى حاكم در جامعه، سالمندان همجنان

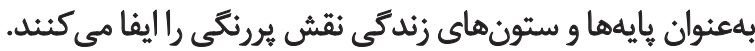

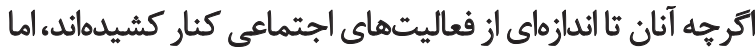

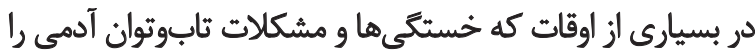

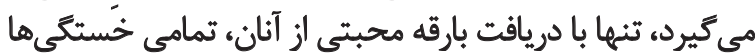

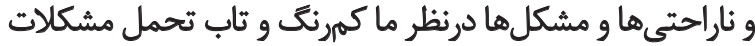

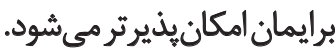

دراينباره يكى از دانشجويان هنين بيان كرد: اتاريخ امتحان

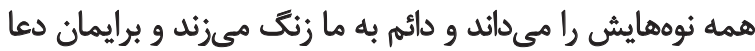

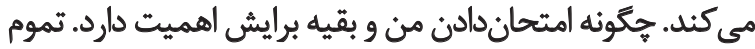

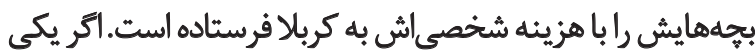

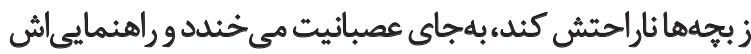
مى كند و راه درست را به او نشان ميدهديه.

در اين زمينه شركت كننده ديكرى كفت: (اقوتى به خانه آنها

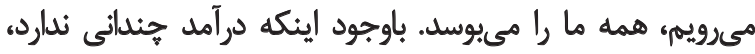


مى تواند زمينههاي رنجش اطرافيان و سالمند را فراهم آورد. در

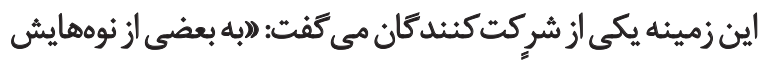
درمجموع ينجاه دانشجو در مطالعه شركت كردند كه از از

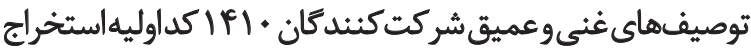

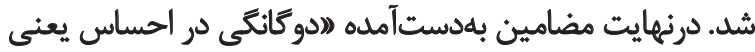

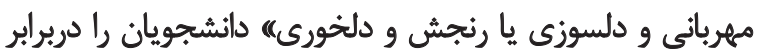

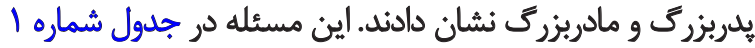
بخش يافتهها درج شده است

مهربانى و دلسوزى أز مضامين مثبت نكاه دانشجويان در اين مطالعه

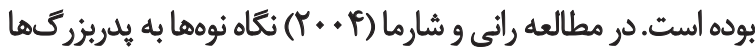

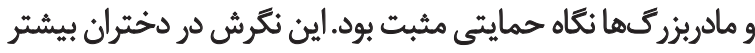

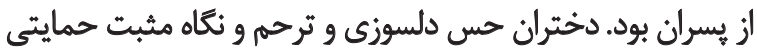

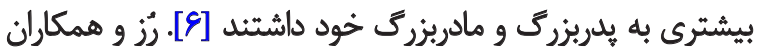

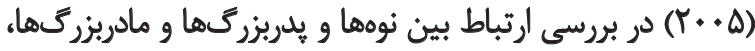

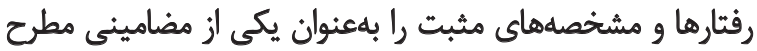

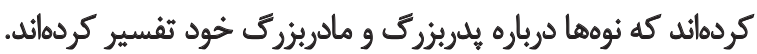

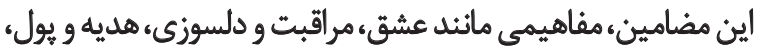
مهربانى، جذابيت و سركرمى و مراقبت را دربرداشت [V] در كزارشى كه مركز مطالعات خانواده و ارتباطات در سال

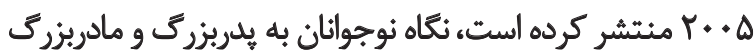

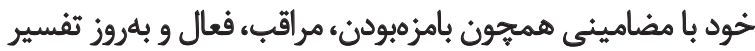

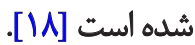

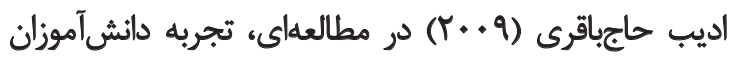

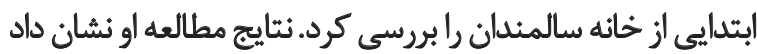

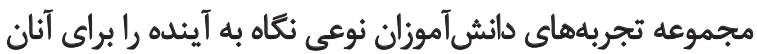

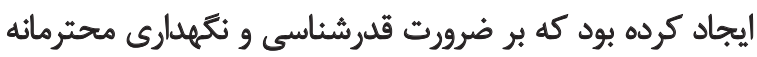

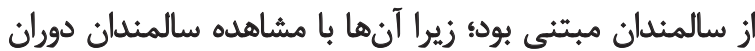

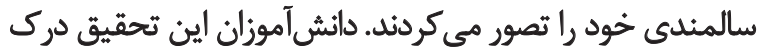

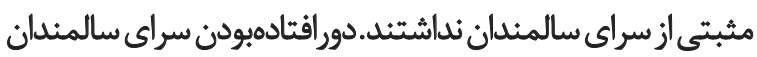

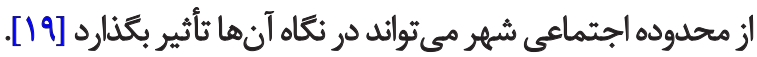

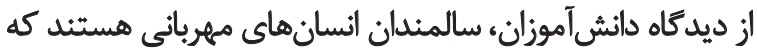

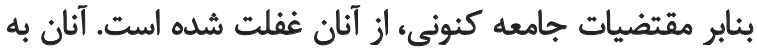

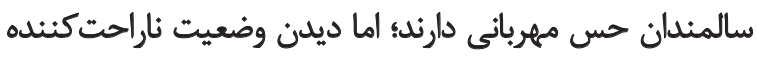

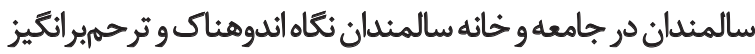

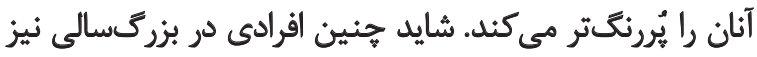

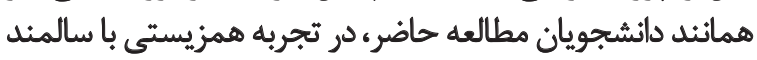

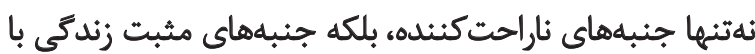
سالمندان رانيز مدنظر داشته باشد.

در مطالعه كارشكى و كراوند (11 + (Y) نكرش دانشجويان بالينى

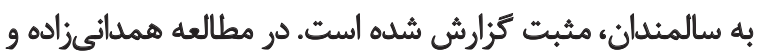

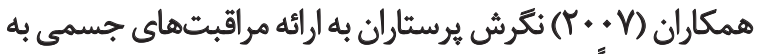

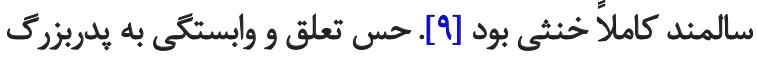

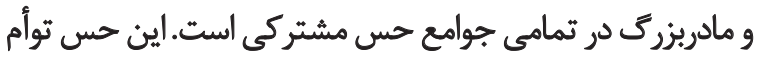

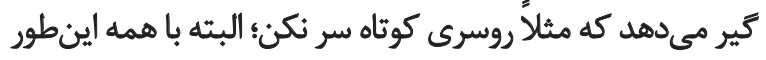

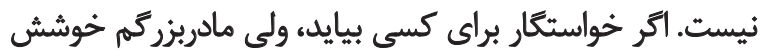

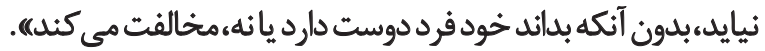
شركت كنئده ديكر كفت: "ايكبار با يكى از دائهايم كه

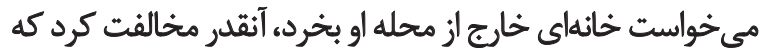

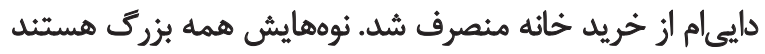

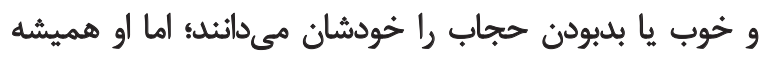

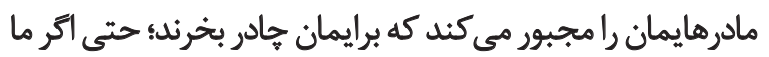
لدوست نداشته باشيمه). شكوه و مَلايه كردن

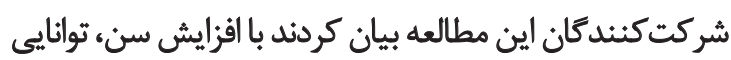

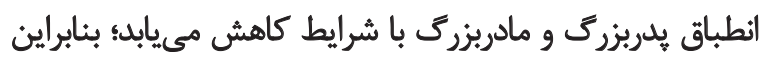

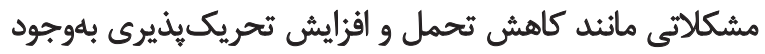

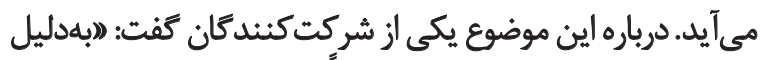

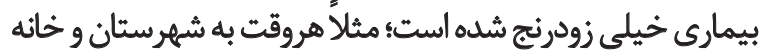

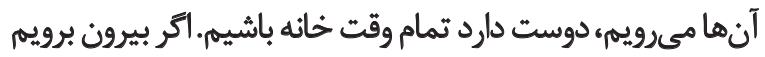

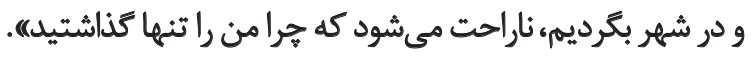
تجربه دانشجوى ديكُرى بهائن شرح بود: لاوقتى در خانه عمويم

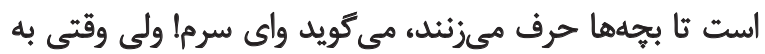

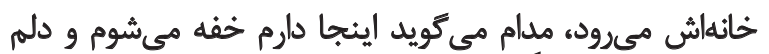

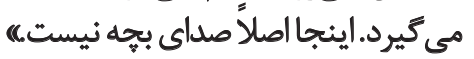
ركتويى ودلشكستن بيان صريح و بدون درنظركرفتن موقعيت افراد در بسيارى مواقع

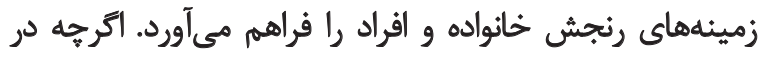

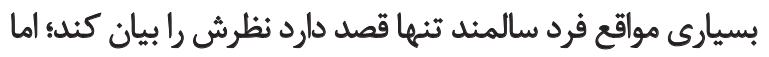

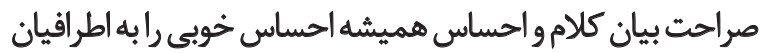

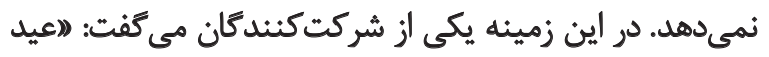

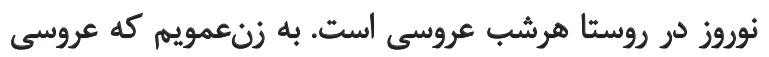

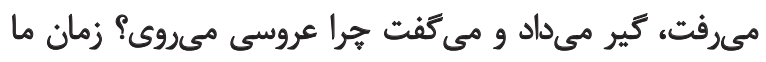

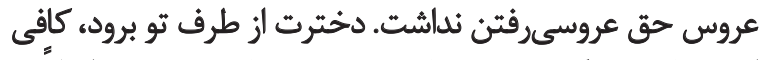

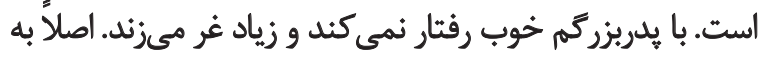

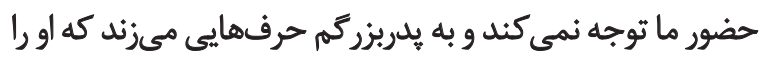

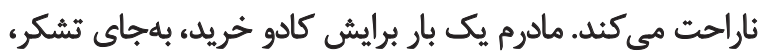
كفت رنكش را دوست ندارده.

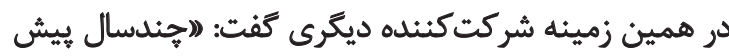

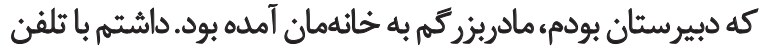

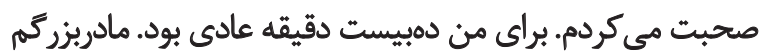

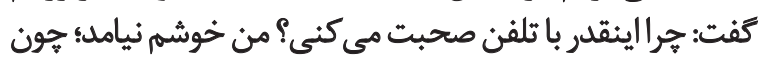
يدر و مادرم مشكلى نداشتندها. 
دانشجويان يا بهعبارت ديكر نسل سوم در ارتباط با سالمندان نتاه

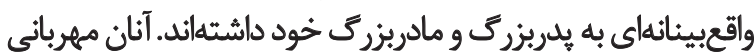

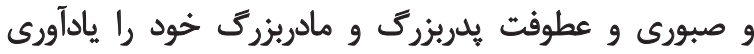

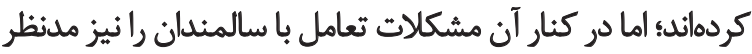

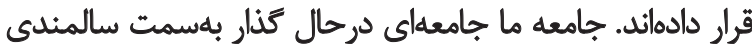

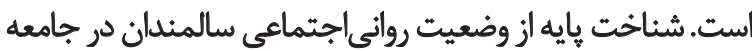

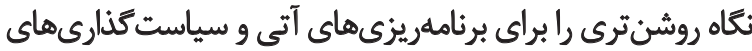

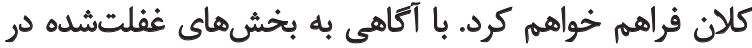

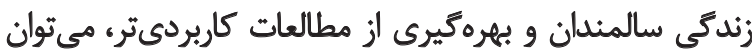
برخى از مشكلات اين قشر را برطرف كرد.

محدوديتها

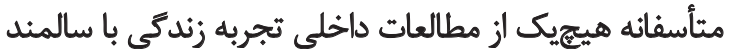

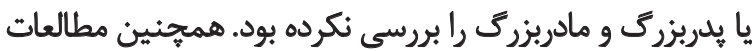

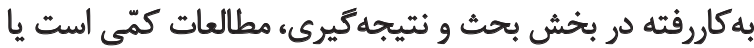

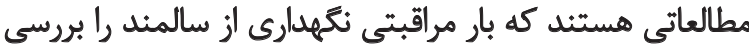

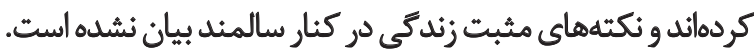

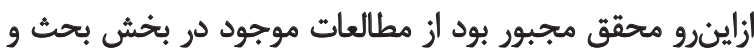
جمعبندى مطالعه حاضر استفاده كند.

بيشنهادها

باتوجهبه تفاوت فرهنگها و نتُشهاى موجود در اين منطقه

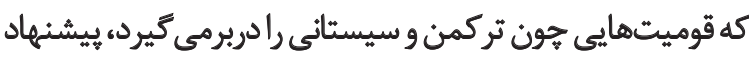
مىشود مطالعات آتى در اين بسترهاى فرهنئى انجام شود.

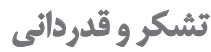

اين مقاله بركفته از طرح بروهشى مصوب كميته تحقيقات

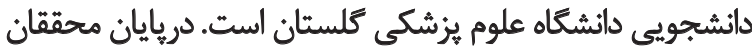

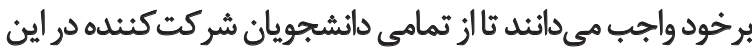
مطالعه تشكر و قدردانى كنيند.
با خاطرات خوب و تصاوير شيرينى است كه ساختار عاطفى ما رام إن

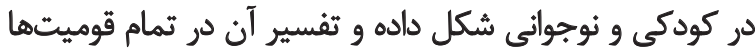

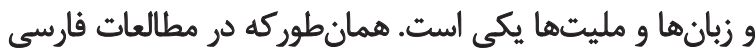

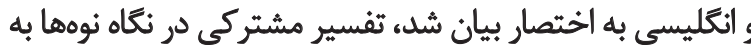

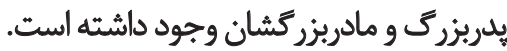

از ديكر مضمونهايى كه از اين مطالعه استخراج شد، مضمون

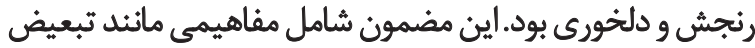

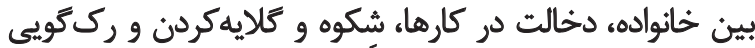

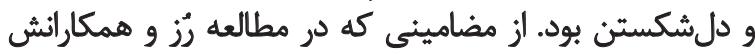

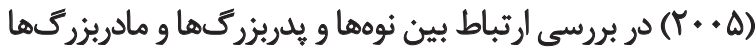

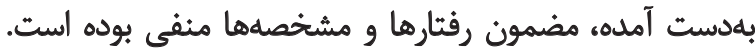

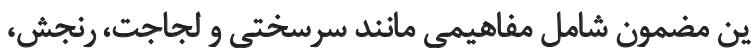

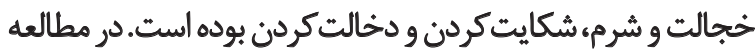

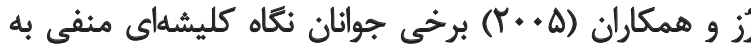

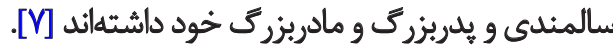

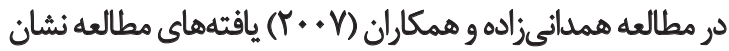

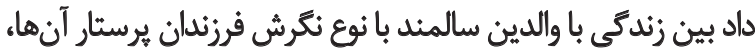

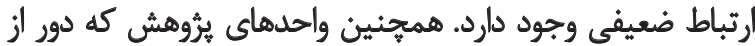

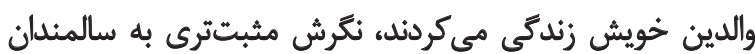

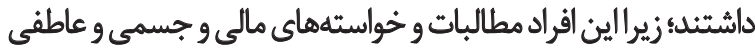

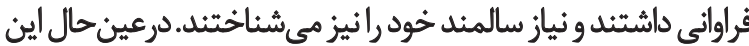

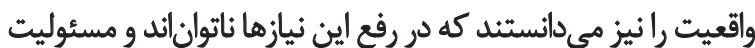

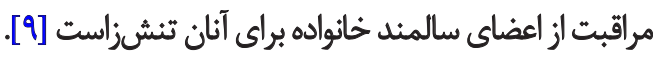

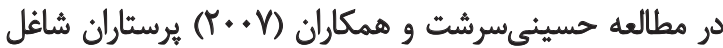

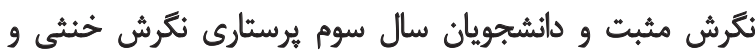

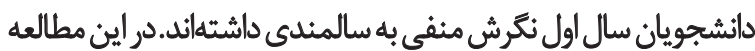

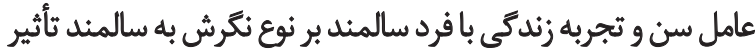

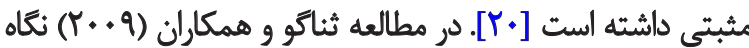

جوانان با تحصيلات بيشتر به سالمثد منفىتر بوده است [ئ] در كنار مضامين مثبت نوهها به تجربه زندكى شان دئ در كنار

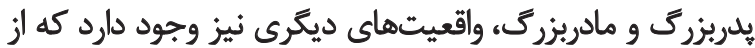

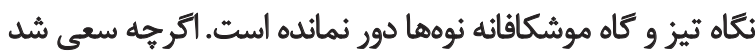

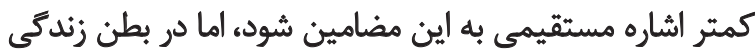

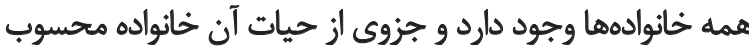

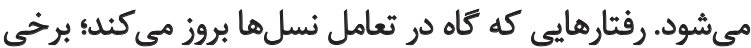

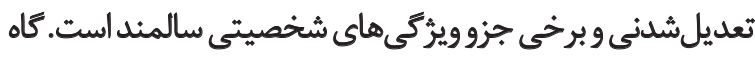

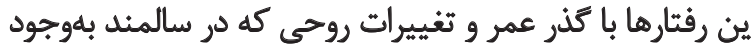

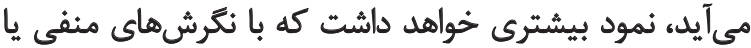
مضامينى خون رنجش و كدورت تفسير مى بشود. نتيجه كيرى نههايى برمبناى يافتههاى اين مطالعه مى توان جنين برداشت كرد كه 


\section{References}

[1] Gholizadeh A, Shirani E. [The relation between personal, family, social and economic factors with therate of life satisfaction of aged people of Isfahan (Persian)]. Applied Sociology. 2010; 21(37):69-82.

[2] Mortazavi S, Eftekhar Ardebili H, Mohamad K, Dorali Beni R. [Assessing the mental health status of elderly in Shahrekord and relationship with sociodemographic factors (Persian)]. Payesh. 2011; 4:485-92.

[3] Delavar B. [Report of senile health status in Islamic Republic of Iran (Persian)]. Tehran: Ketab-e Ashena; 2007.

[4] Sheikhi M. [Sociological study of health and quality of life of Grandparents in Tehran (Persian)]. Journal of Welfare \& Social Development. 2012; 12(2):3-29.

[5] Murphey M, Myers J. Attitudes of children toward older persons: What they are, what they can be. School Counselor. 1982; 29(4):281-89.

[6] Rani R, Sharma S. Attitude of teenagers towards their grandparents. Journal of Human Ecology. 2004; 15(3):183-85.

[7] Ross N, Hill M, Sweeting H, Cunningham-Burley S. Grandparents and teen grandchildren: Exploring Intergenerational Relationships (Research data). Glasgow: University of Glasgow; 2005. doi: 10.5255/UKDA-SN-5231-1

[8] Sanagoo A, Bazyar A, Chehrehgosha M, Gharanjic S, Noroozi M, Pakravan S. [People attitude toward elderly in Golestan province, 2009 (Persian)]. Journal of Research Development in Nursing \& Midwifery. 2009; 8(2):24-9.

[9] Hamedanizade F, Motahedian A, Sarhangi F, Zeighamat F. [Evaluation of nurses atittude about senile physical care (Persian)]. Kowsar Medical Journal. 2007;13(3):258-53.

[10] Haghshenas S. [Family pathology (Persian)]. Tehran: Center for Women and Family Affairs; 2009.

[11] Heravi-Karimavi M, Jadid-Milani M. [Family knowledge about types of abuse in old women in Tehran (Persian)]. Journal of Fundamentals of Mental Health. 2004; 6(23-24):105-10.

[12] Salarvand S, Abedi H. [The elders' experiences of social support in nursing home: a qualitative study (Persian)]. Iran Journal of Nursing. 2008; 20(52):39-50.

[13] Salarvand S, Abedi H, Shamlu K. [The feeling of powerlessness in older people living in nursing homes (Persian)]. Iran Journal of Nursing. 2007; 20(50):60-69.

[14] Mayan M. An introduction to qualitative methods: a training module for students and professionals. Alberta: International Institute for Qualitative Methodology Publication; 2001

[15] Dempsey PA, Dempsey A. Research in nursing: process, critical evaluation and application [M. Salsali, Persian trans]. Tehran: Boshra Publication; 2002.

[16] Hsieh H, Shannon S. Three approaches to qualitative content analysis. Qualitative Health Research. 2005; 15(9):1277-288. doi: $10.1177 / 1049732305276687$

[17] Mayring P. Qualitative content analysis. Forum Qualitative Social Research. 2000; 1(2):365-80. doi: 10.1007/978-94-017-91816_13
[18] Centre for Research on Families and Relationships. Relationships between grandparents and teenage grandchildren. 2005; Edinburgh: Centre for Research on Families and Relationships Publication.

[19] Adib-Hajbaghery M, Aminolroayaee Yamini A. [The experiences of Kashan's elementary students of the elderly hospice (Persian)]. Journal of Behavior Sciences Research. 2009; 9(2):123-32.

[20] Hosseini Seresht A, Nasiri Ziba F, Kermani A, Hosseini F. [Assesment of nursing students and clinical nurses' attitude toward elderly care (Persian)]. Iran Journal of Nursing. 2007; 19(45):57-67. 